\title{
A new look at the serology of treponemal disease
}

\author{
PAULINE O'NEILL \\ Department of Clinical Microbiology, St Thomas' Hospital, London, SE1 7EH
}

\section{Summary}

The serology of treponemal disease has become simpler and more rational in recent years, mainly as a result of the widespread adoption of specific antibody tests and the use of monospecific fluorescent antibody procedures which give information about the immunoglobulin class of antibodies. A set of tests which has proved particularly useful in routine diagnosis is the following: quantitative TPHA test, quantitative VDRL test, and monospecific (IgG and IgM) FTA-ABS tests. This combination is especially valuable in the assessment of new patients with positive results to serological tests and in the management of patients with treated syphilis.

\section{Introduction}

The changes that have recently taken place in the serology of treponemal disease have fortunately tended to make the subject less complicated and more rational than it was in the past; the change that has contributed most of all to this simplification is the widespread adoption of specific antibody tests, in place of the older non-specific ones, in routine testing. To explain how this change has altered the serodiagnosis of treponemal infection it is necessary to discuss briefly syphilis antibodies in general and the tests used to detect them.

Fig. $1 a$ is a conventional classification of syphilis antibodies and shows them divided into those directed against treponemal antigens, specific and non-specific, and those directed against lipoidal antigens; it suggests that the lipoidal antigens may not be of treponemal origin, and is consistent with the view, still held by some, that the stimulus to antilipoidal antibody production in syphilis is a lipoidal substance derived from the host's own tissues. Those who do not agree with this view prefer a slightly different classification of syphilis antibodies (Fig. 1b) since they believe that all the antibodies produced in syphilis are antitreponemal. According to this view, lipoidal antigens are simply non-specific antigens possessed by most treponemes and, to confuse the issue, by many mammalian tissues also. This second type of classification, in which antilipoidal antibodies Based on an address given at the MSSVD and RCOG Joint Postgraduate Meeting, February 21, 1975 Address for reprints: as above
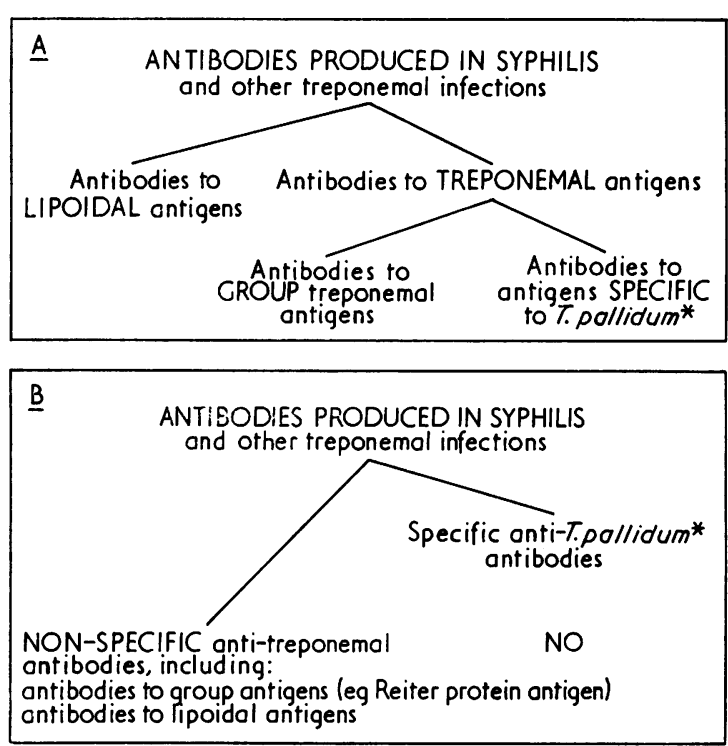

FIG. 1 Two classifications of syphilis antibodies

* Treponema pertenue and Treponema carateum are indistinguishable from $T$. pallidum in serological tests

are regarded simply as a variety of non-specific antitreponemal antibody, is the one used here.

Table I shows some of the tests used to detect syphilis antibodies. The tests, like the antibodies, fall into two groups: those detecting specific antiTreponema pallidum antibody and those detecting non-specific antitreponemal antibody. A point to notice about the specific antibody tests is that they are all of fairly recent date; before 1949, when the T. pallidum immobilization test (TPI) was introduced, physicians had to rely entirely on the often misleading non-specific tests. The reason for the delayed appearance of the specific tests was the difficulty serologists had in growing enough $T$.

TABLE I Some commonly used tests for antitreponemal antibodies showing the dates when they were first described

\begin{tabular}{ll}
\hline Tests for specific anti- $T$. pallidum antibodies \\
TPI & $T$. pallidum immobilization test (1949) \\
FTA-ABS & Absorbed fluorescent treponemal antibody test (1964) \\
TPHA & $T$. pallidum haemagglutination assay (1967) \\
\hline Tests for non-specific antitreponemal antibodies \\
WR & Wassermann reaction (1906) \\
Kahn test & (1928) \\
VDRL (Venereal Disease Reference Laboratory) test (1946) \\
RPCFT $\quad$ Reiter protein complement-fixation test (1953) \\
\hline
\end{tabular}


pallidum to use as antigen. Although we still cannot grow $T$. pallidum outside the living body, the problem of not having enough for diagnostic testing has been solved by a technical advance of a different kind, namely the development of micro techniques.

Versions of specific antibody tests using very minute amounts of $T$. pallidum are now widely available-in particular the micro fluorescent treponemal antibody absorption test (FTA-ABS) (O'Neill and Johnson, 1971) and the micro $T$. pallidum haemagglutination assay (TPHA) (O'Neill, Warner, and Nicol, 1973). It is the introduction of these specific tests into routine testing at clinic level that has contributed more than anything else to the simplification and rationalization of treponemal disease serology.

Without going into detail about the techniques of these tests, it is worth mentioning how simple and economical they are by comparison with the laborious tests of the past. This is especially true of the TPHA test; there is practically no limit to the extent to which this simple process can be scaled up, so that hundreds or even thousands of antibody screening tests can be set up in just a few minutes. Our own laboratory now tests sera in blocks of 120 at a time, using simple equipment costing about $£ 200$. The micro FTA-ABS is not quite as simple as the micro TPHA but it is a great improvement on the old single immunofluorescence tests of 10 years ago. Many laboratories test 10 or 12 sera on the same microscope slide, and some, like ourselves, also process these tests in blocks, using simple mechanical aids.

To turn to clinical problems: now that specific antibody tests are widely available, which tests should one do, and when? To answer this question we first need to consider what sort of antibody, in terms of immunoglobulin class, is detected by each of the tests. Research during the past decade, as summarized by O'Neill (1976), has shown that the lipoidal antigen tests detect mainly IgM class antibody, the TPHA test detects IgG class antibody, and the FTA-ABS test, as it is usually done using the simplest sort of antihuman gamma globulin reagent, also detects IgG class antibody. It is possible, however, by employing monospecific antihuman globulin reagents, to make the FTA-ABS test detect antibody of any immunoglobulin class; and these monospecific FTA-ABS tests are referred to as FTA-ABS IgG, FTA-ABS IgM, and so forth.

Returning to the question of which tests one should use and when, Table II shows a set of four tests, three specific and one non-specific, which when used together provide a surprising amount of information.

\section{TABLE II $A$ useful set of diagnostic tests}

\begin{tabular}{ll}
\hline VDRL slide test & (Quantitative) \\
TPHA & detects IgM class antibody (mainly) \\
FTA-ABS IgG & detects IgG class antibody \\
FTA-ABS IgM & detects IgG class antibody \\
\hline
\end{tabular}

These tests taken together are so informative because the four antibodies concerned do not all behave in the same way in different clinical situations, and it is thus possible to recognize reaction patterns characteristic of certain situations. This is illustrated in Table III. Even more information can be obtained from the four tests if one quantifies two of them (Table IV); without quantification all stages of untreated infection except the very earliest look much the same; using quantification one can see very obvious differences. Similarly differences can be seen between the various groups of treated patients. At this point it may be helpful to go into a little detail about the significance of TPHA titres. In untreated early syphilis the TPHA titre (Table IV) is a good guide to the duration of the infection, except in patients with re-infections, in whom residual antibody from earlier infection may confuse the picture. In treated patients, TPHA titres reflect the stage at which the infection was arrested, since in general TPHA titres decline only slowly after treatment. A TPHA titre inappropriate to the clinical situation may suggest that a patient is undergoing a re-infection rather than a first infection; an example of this would be a patient with a primary chancre and a TPHA titre of, say, 1 in 1,280. Although in this sort of case the lesion may also be atypical, this is not always so.

If we now re-examine Table III, it is clear that this apparently complicated set of reaction patterns is, in

TABLE III Characteristic reaction patterns

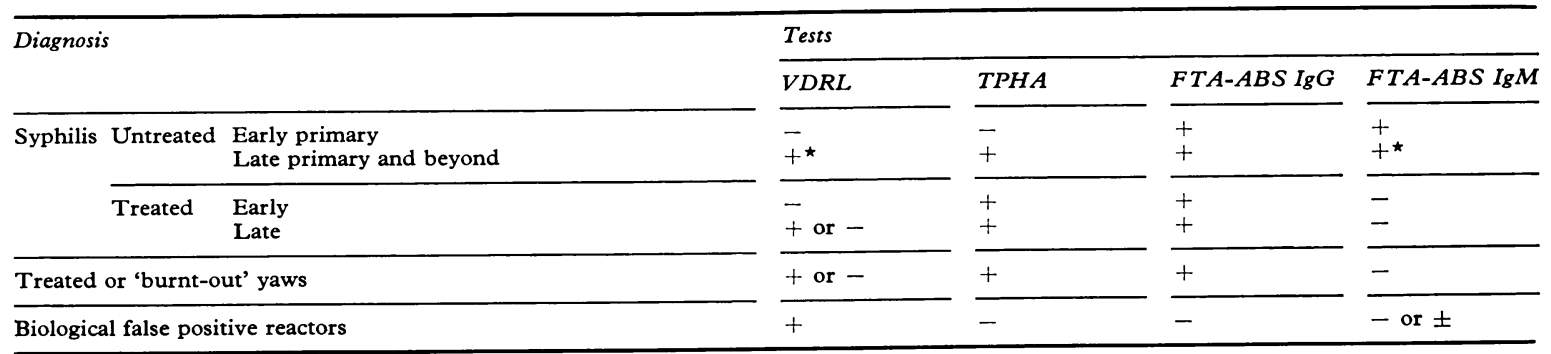

^Some apparently untreated latent cases eventually become negative 
TABLE IV Extra information from antibody titres

\begin{tabular}{|c|c|c|c|c|c|c|c|c|c|}
\hline \multicolumn{2}{|c|}{ Typical reaction patterns } & \multicolumn{4}{|c|}{ Qualitative } & \multicolumn{4}{|c|}{ Quantitative* } \\
\hline 1020 & & $V D R L$ & TPHA & $I g G$ & $I g M$ & $V D R L$ & $T P H A$ & $\operatorname{Ig} G$ & $\operatorname{Ig} M$ \\
\hline Untreated syphilis & $\begin{array}{l}\text { Primary (not early) } \\
\text { Early secondary } \\
\text { Late secondary }\end{array}$ & $\begin{array}{l}+ \\
+ \\
+\end{array}$ & $\begin{array}{l}+ \\
+ \\
+\end{array}$ & $\begin{array}{l}+ \\
+ \\
+\end{array}$ & $\begin{array}{l}+ \\
+ \\
+\end{array}$ & $\begin{array}{r}4 \\
16 \\
64\end{array}$ & $\begin{array}{r}80 \\
320 \\
5,120\end{array}$ & $\begin{array}{l}+ \\
+ \\
+\end{array}$ & $\begin{array}{l}+ \\
+ \\
+\end{array}$ \\
\hline
\end{tabular}

^Reciprocal titres

fact, the result of the operation of three quite simple rules:

(1) In active untreated infection both IgG class and IgM class antitreponemal antibodies are present.

(2) After arrest of infection IgM class antibodies tend to disappear while IgG class antibodies remain.

(3) In developing infection fluorescent antibodies appear before other antibodies.

The evidence on which Table III is based was collected during research studies of individual patients carried out during the past 5 years at St. Thomas' Hospital (O'Neill, 1976). Each patient was studied over a period of time using the four tests, all of which were quantified. Although a full account of this research cannot be given here, the cases illustrated in Figs 2 and 3 are typical of many others followed during the study, and illustrate the three rules.

Experience at St. Thomas' Hospital in the last 5 years suggests that, among various possible applications, there are two areas in which the new tests are especially valuable: the assessment of new patients presenting with positive serological results, including those from yaws areas, and the management of patients with treated syphilis. They are also useful in

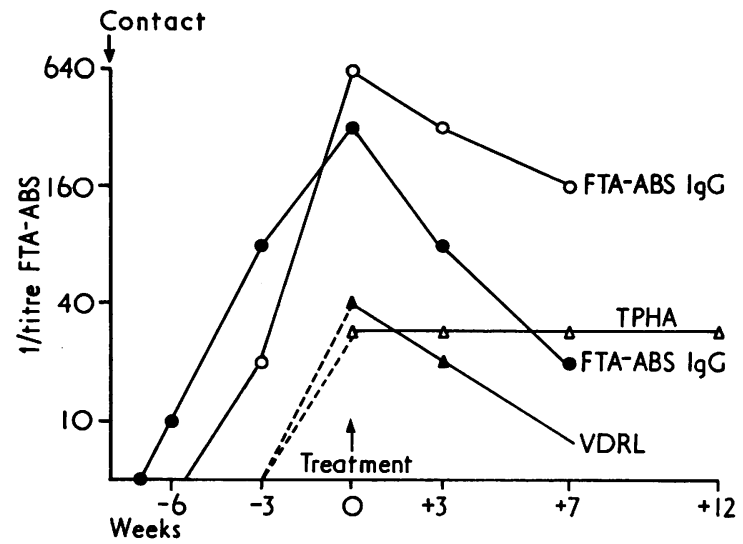

FIG. 2 Developing early syphilis, showing SPECIFIC anti-T. pallidum fluorescent antibodies, TPHA, and $V D R L$ antibodies the detection (but not the exclusion) of congenital syphilitic infection in new-born infants. It will be helpful if we now examine these three situations in more detail.

\section{(1) Assessment of new cases}

For this, a rearranged version of Table III is useful (Table V). In clinics where all four tests shown in the Table are immediately available, it is possible for the physician to have a fairly clear picture of the sort of case he is dealing with by the time the patient comes for his second visit. Further questions can then be asked, and in appropriate cases the clinician may be able to say 'the blood tests suggest that you have had syphilis in the past', or 'the tests suggest that you have recently become re-infected with syphilis'. This approach often encourages the patient to give further information about previous infections and contacts.

\section{(2) Seropositive patients from yaws areas}

The need here is to identify those who are suffering from venereal syphilis. Since virtually all old yaws cases have one of the 'inactive' serological patterns (patterns 3, 4, and 5 in Table V), we immediately suspect recently acquired syphilis if we see either

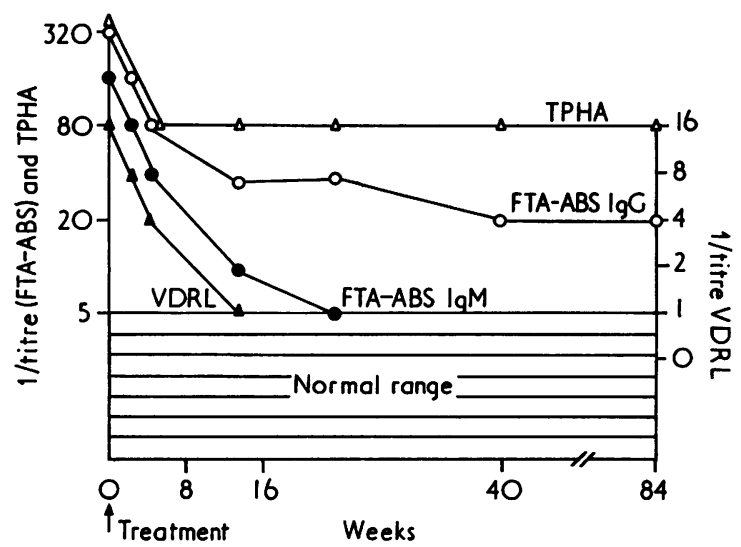

FIG. 3 Late primary syphilis. Decline of SPECIFIC anti-T. pallidum fluorescent antibodies, TPHA, and VDRL antibodies, after treatment 
TABLE V Serological patterns, and their interpretation

\begin{tabular}{|c|c|c|c|c|c|}
\hline \multicolumn{5}{|c|}{ Serological pattern } & \multirow{3}{*}{ Conditions in which this serological pattern is typical } \\
\hline \multirow{2}{*}{$\begin{array}{l}\text { Pattern } \\
\text { number }\end{array}$} & \multirow{2}{*}{$V D R L$} & \multirow{2}{*}{ TPHA } & \multicolumn{2}{|c|}{$F T A-A B S$} & \\
\hline & & & $I g G$ & $I g M$ & \\
\hline 1 & - & - & + & + & Untreated (or recently treated) early primary syphilis \\
\hline 2 & + & + & + & + & $\begin{array}{l}\text { Untreated (or recently treated) early syphilis, except early primary, and } \\
\text { including re-infections } \\
\text { Untreated symptomatic late syphilis (not usually tabes dorsalis, where } \\
\text { patterns } 3 \text { and } 4 \text { are commoner) } \\
\text { Symptomatic late syphilis treated within the preceding } 5 \text { years } \\
\text { Latent syphilis (some cases) }\end{array}$ \\
\hline 3 & $\begin{array}{l}+ \\
\text { (low } \\
\text { titre) }\end{array}$ & + & + & - & $\begin{array}{l}\text { Treated late syphilis } \\
\text { Old yaws (some cases) } \\
\text { Latent syphilis (some cases) } \\
\text { Tabes dorsalis (some cases) }\end{array}$ \\
\hline 5 & - & - & + & - & $\begin{array}{l}\text { Treated primary syphilis } \\
\text { Some cases of old treated or 'burnt-out' treponemal infection }\end{array}$ \\
\hline 6 & + & - & - & \pm or - & Biological false positive reactors \\
\hline
\end{tabular}

pattern 1 or pattern 2 in someone from a yaws area. This approach has been strikingly successful in our clinic during the last 3 years, as venereal syphilis, once rare in young Londoners of West Indian origin, is now on the increase in this group.

Patients who have had syphilis in the past present a problem essentially similar to that of the old yaws patients; here also the appearance of IgM class FTA antibody alerts the physician to the possibility of re-infection. Most of the people seen at St. Thomas' Hospital suffering from early syphilis are homosexual men, and many of them (about 20 per cent.) have had syphilis at least once in the past. It is particularly helpful when dealing with patients in this very high risk category to have a means of detecting early re-infections.

\section{(3) Detection of congenital syphilis in babies born to seropositive mothers}

It is widely believed that the FTA-ABS IgM test performed at birth enables one to exclude congenital syphilitic infection. Unfortunately this is not true; we now know that some babies with the late onset type of congenital infection do not produce $\operatorname{IgM}$ class FTA antibody until they are about 3 months old (Johnston, 1972). However, if IgM class FTA antibody ${ }^{\star}$ is present in neonatal blood and there is no evidence of placental leakage, this can be taken as definite evidence of congenital infection, since it is well established that maternal IgM antibody does not cross the placenta.

Finally, we come to the question, which tests should be chosen for large scale screening of low risk cases ? I think most laboratories would agree that it is

* but see remarks on rheumatoid factor, below not practicable to use fluorescent antibody tests for low risk screening, especially since a combination of TPHA and VDRL tests provides an efficient screen which will detect all varieties of treponemal infection except early primary syphilis. There is unfortunately no easy way of detecting the occasional early primary case in low risk populations; however, if the laboratory is warned that primary syphilis is suspected in a particular patient, an additional FTA test can usually be arranged.

Two problems remain concerning the FTA-ABS IgM test. For technical reasons this is a difficult test to run at a high and controlled level of sensitivity. There is also the problem of preventing antiglobulin antibodies (rheumatoid factors) from interfering in the test (Reimer, Black, Phillips, Logan, Hunter, Pender, and McGrew, 1975); this is usually solved by pre-absorbing sera with aggregated gamma globulin, but as several absorptions may be needed before removal is complete, this can be a time-consuming procedure. The FTA-ABS IgM is thus still a test for the specialist laboratory, but this should not prevent its becoming more widely available as a reference test.

\section{References}

Johnston, N. A. (1972) Brit. f. vener. Dis., 48, 464

O'NeILl, P. (1976) 'Studies of Antibody Production in Syphilis' (to be published)

and Johnson, G. D. (1971) Ann. N.Y. Acad. Sci., 177, 446

-, WARNER, R. W., and NICOL, C. S. (1973) Brit. f. vener. Dis., 49, 427

Reimer, C. B., Black, C. M., Philips, D. J., Logan, L.C., Hunter, E. F., Pender, B. J., and MCGRew, B. E. (1975) Ann. N.Y. Acad. Sci., 254, 77 